EGU2020-18492

https://doi.org/10.5194/egusphere-egu2020-18492

EGU General Assembly 2020

(c) Author(s) 2020. This work is distributed under

the Creative Commons Attribution 4.0 License.

\title{
Seismic Modeling of the Subcrustal Reflectivity Beneath the Iberian Massif (Spain)
}

\author{
Imma Palomeras ${ }^{1}$, Puy Ayarza ${ }^{1}$, Jordi Díaz ${ }^{2}$, Juvenal Andrés², and Ramon Carbonell ${ }^{2}$ \\ ${ }^{1}$ Universidad de Salamanca, Facultad de Ciencias, Geology, Salamanca, Spain (imma@usal.es) \\ ${ }^{2}$ Institute of Earth Sciences "Jaume Almera", ICTJA - CSIC, Barcelona, Spain
}

Sub-Moho reflectors have been identified in seismic refraction and wide-angle reflection recordings in western Iberia since the late '80s. These control source seismic wide-angle shot records have energy large enough to illuminate the uppermost mantle showing strong sub-Moho arrivals at distant offsets $(>180 \mathrm{~km})$ with amplitudes significantly higher than the $\mathrm{Pn}$ and a relatively long coda. The kinematics and wavelet characteristics of these features are probably produced by an increase in P-wave velocity, and forward modeling indicates that these arrivals reflect off an interface in the $60-80 \mathrm{~km}$ depth range beneath the Iberian Massif. The waveform and time length of this arrival suggests that it can result from the interaction of the seismic energy with a $\sim 10 \mathrm{~km}$ thick heterogeneous layer. To test this hypothesis, we used a 2D second-order finitedifference acoustic and elastic full wave-field scheme with a layer consisting of randomly distributed bodies smaller than $1 / 4$ of the wavelength of the seismic waves in thickness and $\Delta V p= \pm 0.2 \mathrm{~km} / \mathrm{s}$ at the considered depth range. Resulting synthetic shot gathers reproduce well the observed amplitudes and codas as a result of the constructive interference caused by the tuning effect produced by this gradient heterogeneous zone. The contrast in physical properties and depth level of this feature are consistent with the top of the phase transition from spinel to garnet Iherzolite, the so-called Hales discontinuity.

Some of the available gathers show a second and deeper reflection. Detailed analysis of the reflected wave-forms suggests that the reflected wavelet has reversed polarity, a feature suggesting. a velocity decrease with depth. Finite difference acoustic and elastic full wave-field modeling places this discontinuity around $90 \mathrm{~km}$ depth beneath the Ossa-Morena Zone (south Iberian Massif). A lateral change is observed beneath the Centro-Iberian Zone (central Iberian Massif) where it is imaged at 103-110 km depth on the southeast and shallows up to $80 \mathrm{~km}$ depth on the northeast. The indicated depth would be consistent with the depth location of the LAB, which is relatively well constrained for the target area by other geophysical observations.

Funding resources: EU EIT-RawMaterials Ref: 17024_20170331_92304; MINECO: CGL2016-81964-REDE CGL2014-56548-P: JCYL: SA065P17). 